\title{
COMPOSITE TRUSS BEAMS EXPERIMENTAL AND THEORETICAL RESEARCH
}

\author{
${ }^{1}$ Peter MICHÁLEK, ${ }^{2}$ Ján BUJŇÁK \\ ${ }^{1,2}$ Department of Building Structures and Bridges, Faculty of Civil Engineering \\ University of Žilina, Univerzitná 1, 01026 Žilina, Slovakia \\ e-mail: 1peter.michalek@fstav.uniza.sk, 2jan.bujnak@fstav.uniza.s
}

Received 2 January 2018; accepted 12 April 2018

\begin{abstract}
The design specifications of composite trusses are only partially included in the European standards. However this construction system can be considered as one of the most economical for building and bridge structures. In general, the composite trusses can be used for greater spans up to the $30 \mathrm{~m}$, which allows better use of internal space without restricting columns. They are appropriate also to meet the requirements for building height limitation, the need to run complex electrical, heating, ventilating, and communication systems. To create the interaction between steel and concrete, it is necessary to prevent the relative slip at the steel and concrete interface using the shear connectors. But the local effects of a concentrated longitudinal force and the distribution of the shear force between steel section and concrete slab, as special task, should be appropriately examined. The finite element analyses can be used to investigate numerically this structural system behavior, exploiting several computer procedures. The experimental research has tested these procedures. The outputs of this study are presented in the paper.
\end{abstract}

Keywords: Composite structure, Connection, Slip, Truss beam test

\section{Introduction}

Classical composite structures consist of steel girders, a concrete slab and connectors, whose function is to provide the interaction between slab and girder. Particularly composite steel-concrete trusses can be considered as one of the most economical systems for building, especially for greater spans allowing better use of internal space without restricting columns. The trusses are appropriate also to meet the requirements for building height limitation as well as the need to run complex electrical, 
heating, ventilating, and communication systems. Also composite steel bridges, whose deck is supported on a filigree steel truss structure and slim piers, are particularly preferable especially to conventional concrete bridges.

In the paper, a method of determining the more exact behavior in steel-concrete beam structures with flexible connectors is presented. To create an interaction between steel parts and concrete, it is necessary to prevent the relative slip at the steel-concrete interface using shear connectors. But the local effects of a concentrated longitudinal force and the distribution of the shear force between steel section and concrete slab, as special task, should be appropriately examined. There is no particular recommendation for the design of composite truss, except the formulas in Eurocode 4 [1], clause 6.6.2.3 for the local effect of a concentrated longitudinal force and the distribution of the longitudinal shear force into local shear flow between steel section and concrete slab.

In the case of a composite truss, the longitudinal forces are introduced into the concrete slab similarly only locally in the nodes, where the web members are connected to the compressed chord Eurocode 4 [2]. The finite element analyses can be used to investigate numerically this structural system behavior, exploiting several computer procedures. Nowadays, different types of shear connectors are used. In this investigation, shear connection is developed using the welded headed studs. The proposed procedures are based on the results of recently completed experimental research. The outputs of this research are presented in the paper.

\section{Composite truss beam tests}

To analyze the global behavior of steel-concrete composite trusses, experimental program was implemented [3]. Four similar steel-concrete composite truss beams of span $3.75 \mathrm{~m}$ were prepared. Steel truss components were made from the steel S235. Upper chord of the beam was prepared from $1 / 2$ IPE 160 , bottom chord from two welded UPE 120 in box component. The web members at lateral parts consisted of square hollow section SHS 70x70x6.3 and the middle diagonals of the square hollow section SHS 40x40x3. Concrete slab of size $800 \times 100 \mathrm{~mm}$ was made with demand on concrete grade $\mathrm{C} 25 / 30$. Transversal and longitudinal reinforcement was formed from the bars $\phi 10$. Shear connection was provided by headed stud of diameter $10 \mathrm{~mm}$ and height $50 \mathrm{~mm}$ located only above the nodes as it shown in Fig. 1.

Experimental testing using progressively static loading applied in the thirds of span above nodes is illustrated on the third truss specimen (Fig. 2). Strains were recorded in both chords and web members of the girders as well as concrete slab by system of sixteen strain gauges.

The details positions of the devices for strain registration in cross sections are labeled as T1 to T16. During the testing, the end slips of concrete slab have been measured using displacement sensors as P19 to P22. The deflection transducers were situated at the girders ends as well as in the middle P16 and the ones P14, P18 near the quarter part of span, as it is shown in Fig. 3. Data received from the strain gauge package were digitized and sent to the notebook. This computer was used to communicate with the measurement system for commands regarding data acquisition, 
downloading and display. Thus, reliable system already approved in the previous testing, reported in [4].

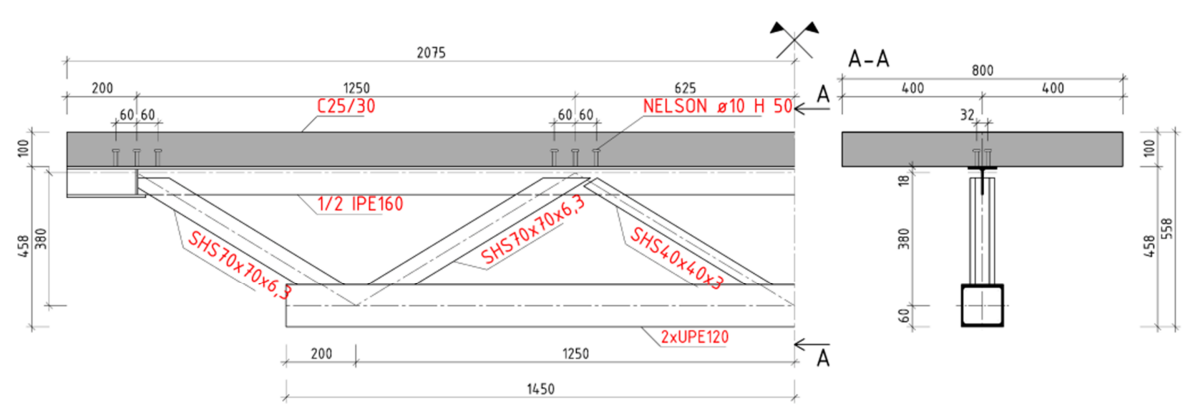

Fig. 1. Components of composite truss specimen
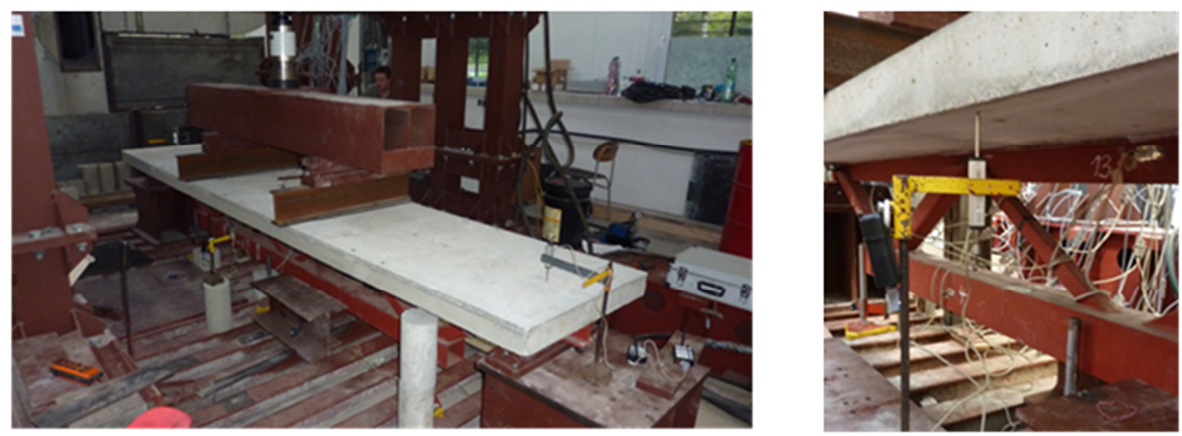

Fig. 2. Loading and general view on measurement system

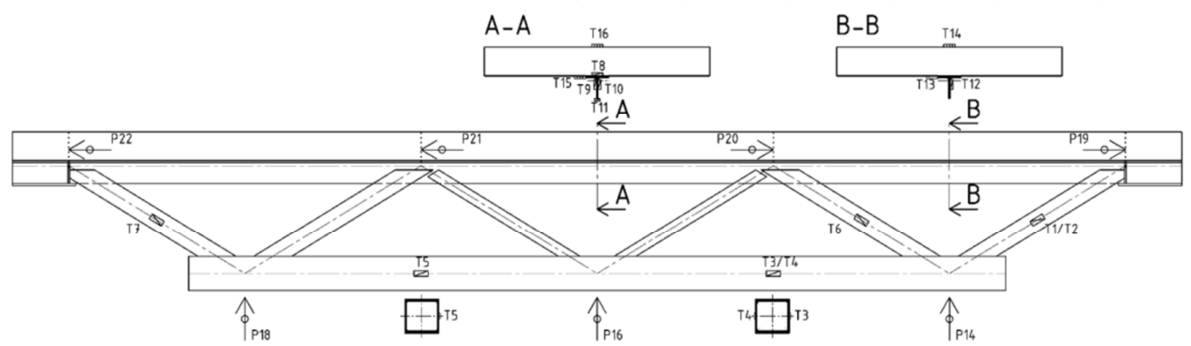

Fig. 3. Deflection, slip and stress sensors arrangement

The recorded deflections have been initially developing proportionally till the loading level of $325 \mathrm{kN}$. This maximum value of elastic load carrying capacity is in appropriate correlation with the result of the analyses according to Eurocode 4 [2]. The whole truss deflections under supplementary loading have been growing slightly 
nonlinearly and produced the ultimate permanent vertical deflection of $33 \mathrm{~mm}$ at the end of test.

Even the stress distribution in strut sections has been initially rather uniform and progress proportionally. However, with increasing loading, the resulting stress patterns have proved different faster development. Especially the upper chord yielded rapidly in the mid-span sections due to combination of bending and compression as a result of significant beam deflections. Finally the chord failed by local instability. The experimental limit load carrying capacity of the specimen was $530 \mathrm{kN}$.

In the beginning, also longitudinal slips in shear connection have been unimportant along the entire composite beam span with a symmetrical distribution to the mid-span. The slip shapes progressively became more irregular and finally fully irreversible. The maximum slip at the truss end was $8.1 \mathrm{~mm}$ and at the opposite beam edge only $5.9 \mathrm{~mm}$. The limit state has been achieved at the load value under which the connectors in the support zone happening to fail by shearing, as it can be seen in Fig. 4. In this stage, the connectors in span were only somewhat distorted by bending thanks to favorable loading. The behavior already identified in the other investigation [5].
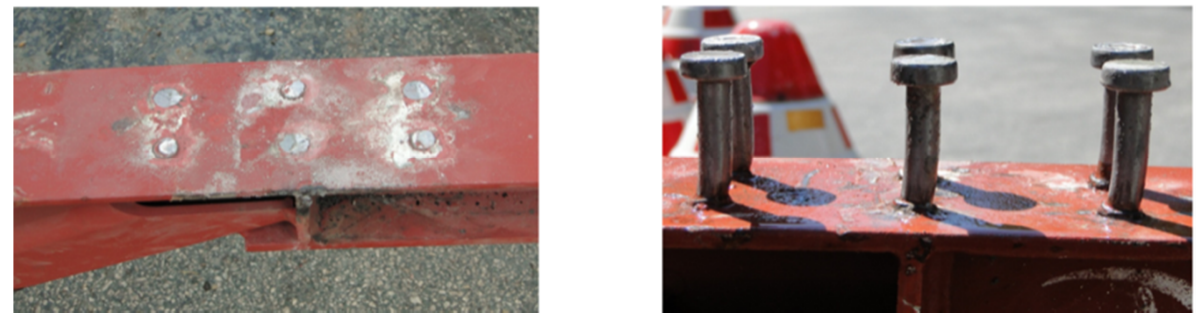

Fig. 4. Shear failure of connectors at the edge zone and in less stressed interior span area

\section{Numerical study of truss shear connection behavior}

The finite element analyses can be used to investigate numerically shear connection of the truss structural system, exploiting several computer procedures. The software CAD of Scia system was used to evaluate the structural behavior of a reference composite truss [6], taken from the above experimental investigation. Serious considerations had to be given to proper representation of the geometric characteristics.

The concrete deck was approximated with shell finite elements. Steel truss components were meshed by member elements On the other hand, material behavior was approximated as linear in this numerical investigation. To simulate the actual composite action of the tested truss, beside real shear headed studs connectors $\phi 10 / 50$ $\mathrm{mm}$ used at the key positions shown in Fig. $5 a$, the others connection models were developed.

The alternative model 1 takes into account influence of surrounding concrete by tube-shaped envelope under stud head of $19 \mathrm{~mm}$ in diameter, as illustrated in Fig. $5 \mathrm{~b}$. Considering second moment of steel shank area $I_{S, S t}=\pi . D_{S, S t}{ }^{4} / 64=491 \mathrm{~mm}^{4}$, the concrete tube can contribute to the resulting sectional characteristic by the value 
$I_{C, C}=5910 \mathrm{~mm}^{4}$. Consequent effective composite connector second moment of area would be $I_{\text {eff }}=1360 \mathrm{~mm}^{4}$.
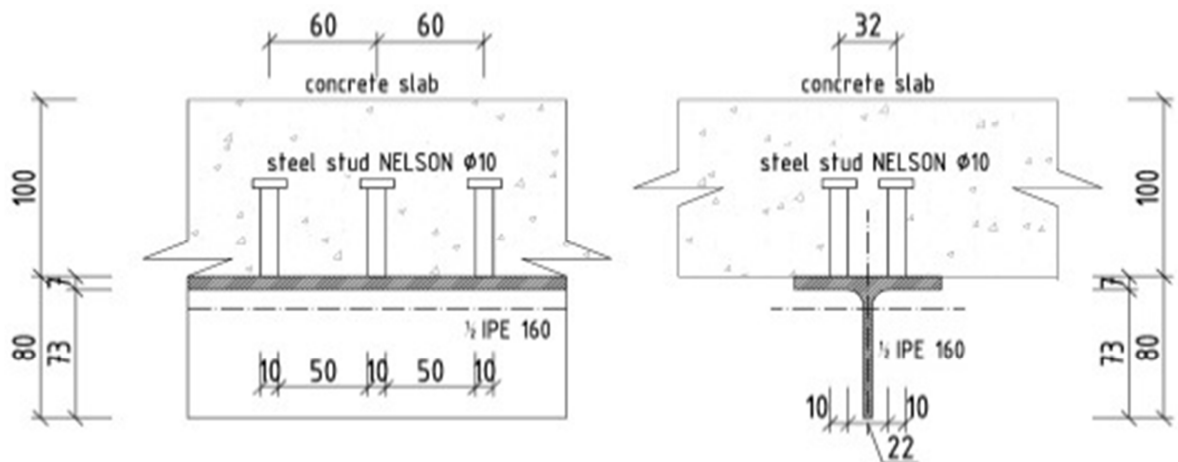

a)
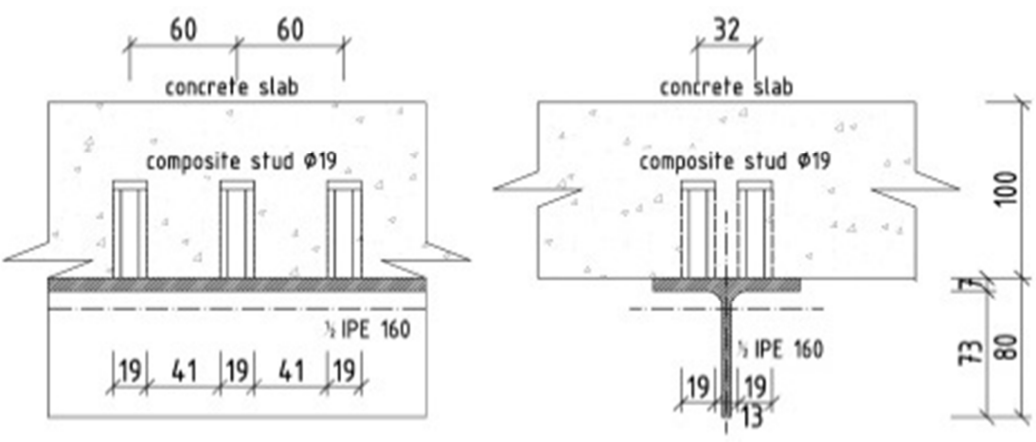

b)

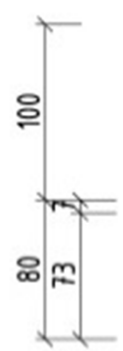

Fig. 5. Real steel connectors, model 1 of composite studs

The experimental deflections, especially in the elastic loading are confronted to predicted numerical values in Fig. 6. This almost linear region of composite truss behavior can be particularly important in the case of cyclical or repeating live actions on bridge structures producing unfavorable fatigue effects.

The progressive stress development during testing, registered by strain gages installed in the mid span of upper chord is alternatively given in Fig. 7. The resulting measured out evolution is also related to theoretical distribution.

Introducing this modified sectional parameter according to the above connection model 1 , the deflections might be more exactly theoretically reproduced, as illustrated by dot-dash line in Fig. 6. But in the case of normal stresses the accuracy seems inferior, as it can be seen in Fig. 7.

For this reason, the next stud connector model 2 according to Fig. $8 a$ may consider slight larger concrete cylindrical stud cover entirely of $33 \mathrm{~mm}$ in diameter. The second moment of its area would increase at $I_{C, C}=57700 \mathrm{~mm}^{4}$. Thus effective value of this parameter will be greater and equal to $I_{\text {eff }}=9010 \mathrm{~mm}^{4}$. From dash line in Fig. 6 and 
Fig. 7, it is evident improved agreement in stress development, but inferior accordance of deflections progress.

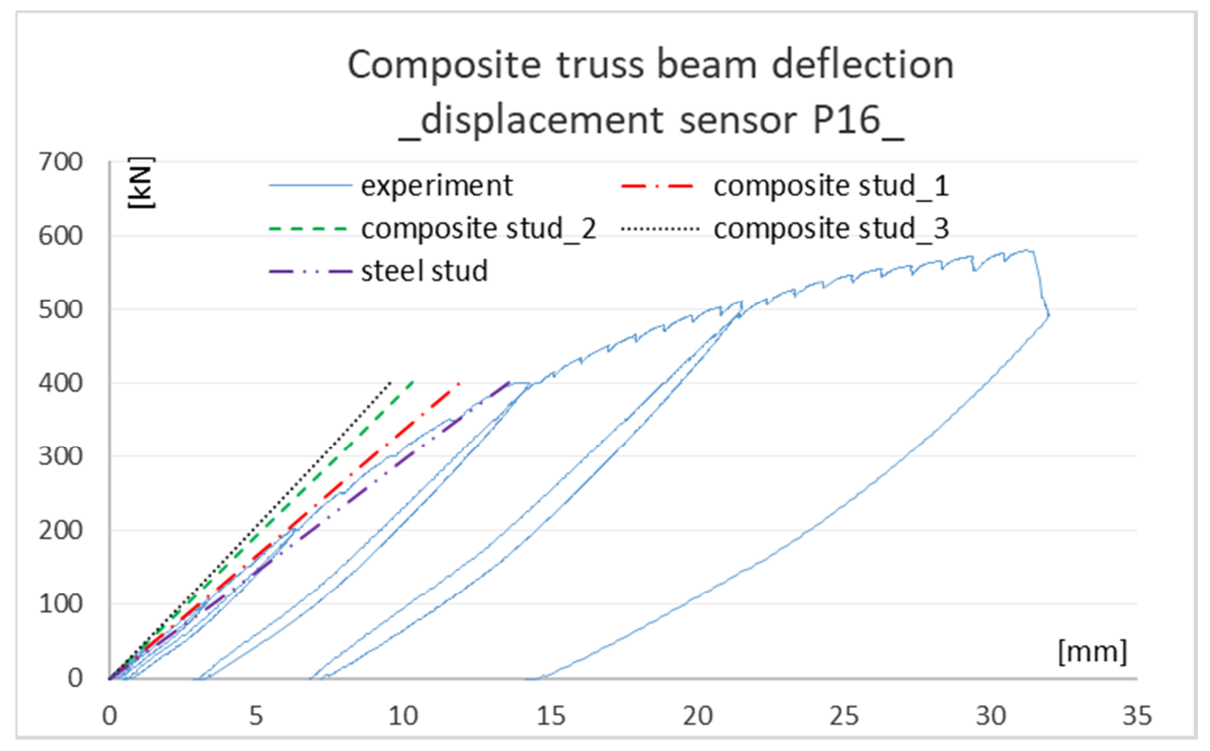

Fig. 6. Composite truss deflections (P16)

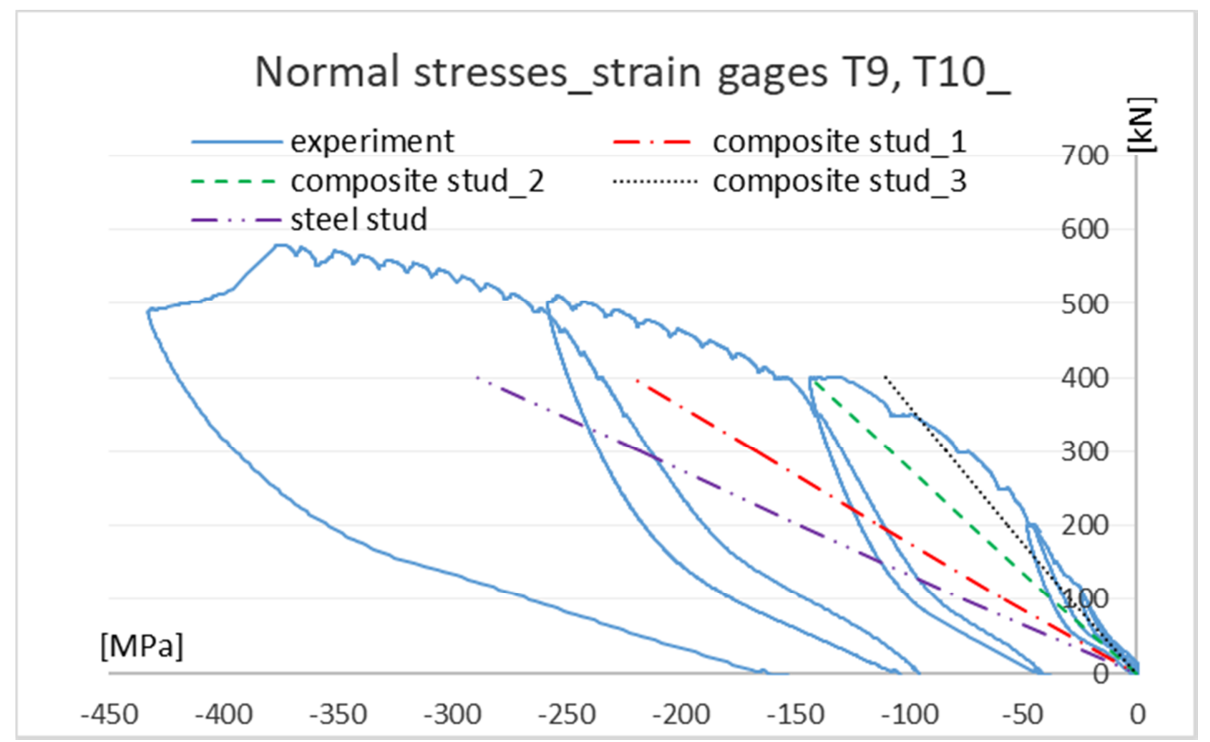

Fig. 7. Normal stresses (T9 and T10) in the mid-span 
The in-between shape model 3 might simulate composite stud as a tapered concrete cone, surrounding steel shank with its diameter of $20 \mathrm{~mm}$ at top and $80 \mathrm{~mm}$ in bottom base, as it is shown in Fig. $8 b$. Due to limit mutual pitch, a cone intersection usually can arrive. The approximation to the cylinder should be generally imposed using equality of volume of both connection bodies. In this example, the real cone-shaped connector volume is $V_{c}=91300 \mathrm{~mm}^{3}$. The equivalent diameter of cylinder-shaped composite stud would be $50 \mathrm{~mm}$ with the second moment of area $I_{C, C}=327000 \mathrm{~mm}^{4}$ and the effective value of this sectional characteristic $I_{\text {eff }}=48800 \mathrm{~mm}^{4}$.

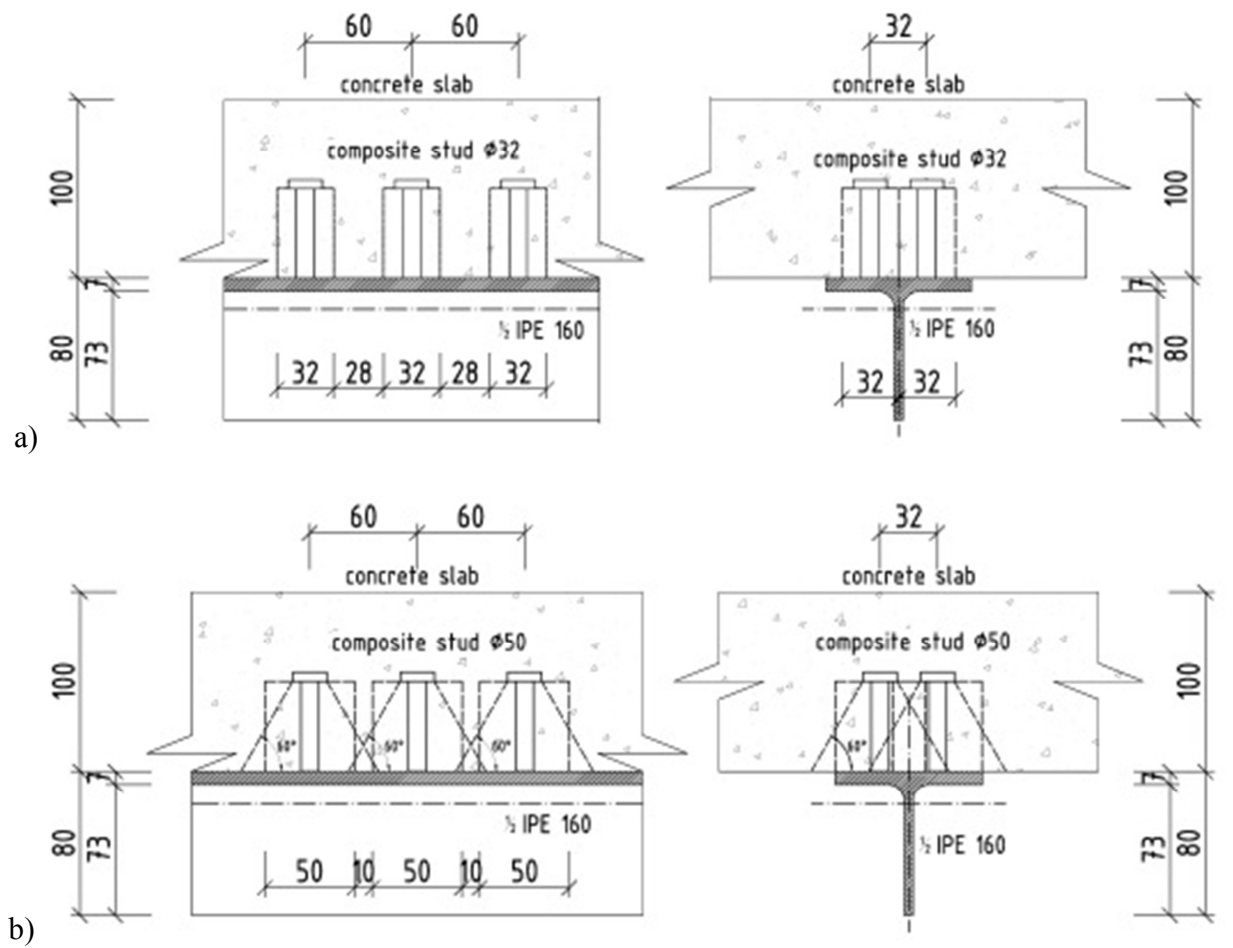

Fig. 8. Different cylinder-shaped model 2 and conic model 3 of composite studs

The dotted lines in Fig. 6 and Fig. 7 indicate even stronger conformity of stresses results. But inversely, it is seen a significant drop of accuracy between theoretical and experimental deflection values.

\section{Remarks and final conclusions}

In the paper, the experimental and calculating procedures of the steel-concrete composite trusses with flexible stud connectors were presented. The experimental investigation was performed on the similar test composite truss specimens. 
In the proposed procedure, the four different stud connectors models were developed and exanimated. They were additionally verified by the results of measurements. The comparison of experiment results and recommended theoretical curves confirm a good agreement in deflection development of the model 1 considering concrete tubeshaped envelope under stud head. However, model 3 simulating composite stud as a tapered concrete cone can provide higher accuracy in stresses. The calculation models can reflect more really trusses behavior, especially in linear loading region, when compared to the actually standard procedure. Generally, the comparisons are in good agreement with the numerical result, if the extremely complex character of composite truss is considered.

\section{Acknowledgment}

The paper presents results of the research activities supported partly by the Slovak Cultural and Educational Grant Agency; grant No. 019ŽU-4/2016 and Science Grant Agency project No. 1/0343/18.

\section{References}

[1] Eurocode 4, Design of composite steel and concrete structures, Part 1-1, General rules and rules for buildings, March 1992.

[2] Eurocode 4, Design of composite steel and concrete structures, Part 2, Bridges, July 1996.

[3] Bujňák J., Perkowski Z. Performance study of composite truss, Conference Proceedings of the 4th International Conference on Contemporary Achievements in Civil Engineering, Subotica, Serbia, 22 April 2016, p. 165-172, http://www.gf.uns.ac.rs/, (last visited 10 November 2107).

[4] Bujňák J., Bouchaïr A. Theoretical and experimental research on steel-concrete composite truss, Proc. of the 37th IABSE Symposium, Madrid, Spain, 3-5 September 2014, Publisher: IABSE C/o ETH Hönggerberg, CH-8093 Zürich, Switzerland, pp. 478-479.

[5] Bujňák J., Furtak K. Connection slip in composite elements under quasi-long-term actions, Pollack Periodica, Vol. 9, No. 2, 2014, pp. 29-34.

[6] Ďuratná P., Bujňák J., Bouchaïr A. Behavior of steel-concrete composite trusses, Pollack Periodica, Vol. 8, No. 2, 2013, pp. 23-28. 